\title{
Lessons From Near-Death Experiences for Humanity
}

\author{
Craig R. Lundahl, Ph.D. \\ Western New Mexico University
}

ABSTRACT: A considerable amount of information on the aftereffects of near-death experiences (NDEs) has been gathered by researchers and used by practitioners to help NDErs, but the lessons from this information have not been presented for use by the rest of humanity. This essay summarizes nine lessons consistently gleaned from NDEs, which may help motivate humanity to live more in accordance with the messages from NDEs.

The aftereffects of near-death experiences (NDEs) have been described since the commencement of modern near-death studies in 1975 with the publication of Raymond Moody's Life After Life. Although most early near-death researchers focused on the phenomenology of the experience, many of those same investigators also observed the aftereffects of the experience, and found that NDErs outwardly showed measurable changes in attitude and behavior toward life that were attributable to the NDE.

Moody (1975) reported that NDErs felt their experiences broadened and deepened their lives, caused them to become more reflective and

Craig R. Lundahl, Ph.D., is Professor of Sociology and Business Administration and Chair of the Department of Social Sciences at Western New Mexico University. This research was supported by a sabbatical leave granted by the Sabbatical Leave Committee of Western New Mexico University. 
more concerned with philosophical issues, changed their attitude toward physical life, changed their concepts of the mind and its importance, taught them the importance of cultivating love for others, taught them the importance of seeking knowledge, and changed their attitude toward physical death.

Stanislav Grof and Joan Halifax (1977) described a pattern of change in NDErs that included a reduced fear of death, improved well-being, and enhanced meaning in life.

Kenneth Ring (1980) found in his systematic study of the NDE that the typical near-death survivor emerged from the experience with a heightened sense of appreciation for life and a determination to live life to the fullest, with a renewed sense of purpose in living, and as a stronger person who valued love and service to others and no longer felt the material comforts in life were important. He also found that NDErs who reported a core experience became more religious, feared death less or lost their fear of death, and believed more definitely in an afterlife. In a subsequent book, Ring (1984) looked at 14 core NDEs that suggested patterns of spiritual awakening. The value changes induced by these NDEs, according to Ring, included enhanced appreciation of life; concern for others; greater self esteem; nonmaterialism; a quest for greater meaning; and changes in religious orientation that were characterized by greater spirituality, perceived closeness to God, de-emphasis of formal religiosity, universalism, increased belief in life after death, and greater receptivity to Eastern beliefs.

Bruce Greyson and Ian Stevenson (1980), in a study of 78 NDErs, found that most reported attitude changes toward God or religion, self, death, and life and its meaning. Greyson later reported that NDEs decreased suicidal ideation (1983a) and led experiencers to judge values related to material and social success as less important (1983b).

In an analysis of the accounts of 215 survivors of life-threatening danger, Russell Noyes (1980) identified a pattern of favorable attitude changes resulting from NDEs, including a reduced fear of death, a sense of relative invulnerability, a feeling of special importance or destiny, a belief in having received the special favor of God or fate, and a strengthened belief in continued existence. He also found several more elements associated with a heightened awareness of death that resulted from the NDE, including a sense of the preciousness of life, a feeling of urgency and reevaluation of priorities, a less cautious approach to life, and a more passive attitude toward uncontrollable events.

Michael Sabom (1982) found that almost all subjects interviewed in his study viewed their NDE as an important event that had done more 
to shape their life goals and attitudes than any other previous experience. Sabom found these NDErs' death anxiety was dramatically reduced or eliminated, and they developed a new fervor for day-to-day living and a new attitude toward death. Their religious views were commonly strengthened by the NDE, and they developed a new personal interest in the caring and loving aspects of human relationships.

Charles Flynn (1982) summarized the attitude and value changes of 21 NDErs as a greatly increased concern for others, a lessened fear of death, an increased belief in an afterlife, an increased religious interest and feeling, and a lessened desire for material success and approval of others. In his subsequent book that described NDE-induced value transformations, he listed those changes as a strong belief that life has inner meaning, a decreased fear of death, an increased belief in an afterlife, a strong desire to love and help others, and an indifference to materialistic and competitive success and status (Flynn, 1986).

George Gallup and William Proctor (1982) reported a variety of NDE aftereffects from the nationwide Gallup Poll. Among these aftereffects were a lessening of fear of death, a strengthening of personal religious beliefs, a heightened perception of life's brevity and a determination to live every moment intensely, a lessening of intimidation by the demands of life, an increased concern about fellow men and women, an increased sensitivity to a place in the world, a feeling of increased control over life, and a desire to sacrifice for others.

Timothy Green and Penelope Friedman (1983) reported that NDErs felt definite changes in values away from materialistic and towards spiritual goals. Their subjects appeared to be more loving and more aware of their relationships with others and more conscious of the meaning and purpose of their lives. Their subjects reported less fear of death or no fear at all, and an unshakable conviction that they would survive physical death.

Steven McLaughlin and Newton Maloney's study of 40 NDErs found an increase in the importance of religion and religious activity (1984). Nina Helene (1984) interviewed 20 Christian NDErs and found their lives were characterized by unusual conversion experiences or deep recommitments and life transformations.

Martin Bauer (1985) found that NDEs brought about positive attitude changes in 28 NDErs. Margot Grey (1985) discussed the positive effects of NDEs on attitudes in her book. Elaine Ann Gomez (1986) described the increases in positive values in ten NDErs.

Cherie Sutherland's study of 50 Australian NDErs (1990) found a significant shift away from organized religion and church attendance and towards private informal prayer and meditation, a belief in life 
after death, a lack of fear of death, and an attitude against attempting suicide. When Sutherland asked the NDErs the most significant change that resulted from their NDEs, spiritual growth, a loving attitude, knowing God, and inner peace were mentioned as the most meaningful changes by the majority of her subjects.

Melvin Morse, who studied the NDEs of children, found many had no fear of death as a result of their NDEs (Morse and Perry, 1990). One child became very religious, while another told him one could be with God without the rules of religion. The children he interviewed also felt that life was precious and had a purpose. Morse reported that one child spoke frequently in grade school about the need to love one another after his NDE, while other children mentioned acquiring knowledge, and learned that little in life is worth getting upset over, and to be more tolerant of other people's beliefs.

A few individuals have described the aftereffects of their own NDEs. P. M. H. Atwater (1988) believed the major aftereffects were the inability to personalize emotions or feelings, the inability to recognize or comprehend boundaries, difficulty understanding time sense, expanded or enhanced psychic sensitivities, a changed view of physical reality, a different feeling of the physical self, and difficulty with communication and relationships.

A review of these studies and first-person accounts shows they are consistent in their findings about the aftereffects of the NDE; they confirm that they NDE effects changes in the experiencers' values, attitudes, and behavior. This considerable accumulation of information on the aftereffects of the NDE has been utilized in an applied setting for the treatment of NDErs by social workers (Clark, 1984), nurses (Corcoran, 1988; Papowitz, 1986), counselors (Furn, 1987; Greyson and Harris, 1987; Miller, 1987; Noble, 1987; Schaefer, 1988), and health care workers (Walker, 1989). Flynn (1986), a sociologist, has used information on the aftereffects of NDEs in the "Love Project" that he incorporated into his courses to foster unconditional love among his undergraduate students who had not had NDEs.

What we see thus far in the field of near-death studies regarding the aftereffects of the NDE is a collection of information on experiencers' changed values, attitudes, and behavior, information accumulated by researchers and used by practitioners to develop therapeutic approaches for helping NDErs deal with their experiences. What seems to be missing in all of this newly acquired pure and applied knowledge is any transmission of it to society. Are there some basic lessons from the NDE for all people?

Surely the sharing of such information can only be a positive contribution to the lives of the general population, much as it has been to the 
lives of NDErs. Of course, some of the work by near-death researchers such as Moody, Ring, and Morse has been popularized by the mass media, but has the public received a deliberate and concise account of these basic lessons in a straightforward manner, or have they received bits and pieces here and there? Could the public decipher these meanings from the numerous scholarly publications on the subject?

I am not sure we can give a positive answer to either of these questions. I believe we have an obligation to share the meaning of these findings with nonNDErs and with those outside the near-death research and practitioner community. Therefore the purpose of this essay is to outline concisely the major lessons from NDEs for humanity.

\section{Lessons From Near-Death Experiences}

An examination of the findings from near-death research and from individual near-death accounts suggests a number of important lessons for humanity. NDEs seem to be telling us all: (1) do not fear death; (2) grow spiritually or religiously; (3) do not take life for granted; (4) love and serve others; (5) each human life has a purpose; (6) there is an afterlife; (7) social position and wealth are not important; (8) do not take your own life; and (9) gain knowledge. An examination of each of these NDE lessons will help clarify them.

\section{Do Not Fear Death}

Probably the most frequently mentioned aftereffect of the NDE is the statement, "I lost all fear of death," or, "I am not afraid to die." After the experience, one NDEr flatly stated: "The terror I had of death is gone" (Nelson, 1989, p. 146). Most NDErs report losing lose their fear of death, and it is reasonable to assume that knowledge of NDEs can help all people to understand the process of death better and to reduce their fear of it as well.

\section{Grow Spiritually or Religiously}

Many NDErs become more spiritual or religious after the NDE. Sabom (1982) found that the religious views of persons who experienced an NDE were strengthened, and this was evidenced by a marked increase in formal religious activity or personal commitment. Gallup also described one of the main results of NDEs as a strengthening of 
personal religious beliefs (Gallup and Proctor, 1982). Ring (1980) concluded that the NDE is a spiritual experience that can produce spiritual behavior. He differentiated between religious and spiritual by quoting a wise man: "A religious person follows the teaching of his church, whereas a spiritual person follows the guidance of his soul" (Moody and Perry, 1988, p. 127). Perhaps Moody best described the message for spiritual or religious growth when he wrote:

The interesting thing is that after the NDE, the effects seems to be the same: people who weren't overtly religious before the experience say afterward that they do believe in God and have an appreciation for the spiritual, as do the people who believed in God all along.

Both groups emerge with an appreciation of religion that is different from the narrowly defined one established by most churches. They come to realize through this experience that religion is not a matter of one "right" group versus several "wrong" groups. People who undergo an NDE come out of it saying that religion concerns your ability to love-not doctrines and denominations. In short, they think that God is a much more magnanimous being than they previously thought, and that denominations don't count. (Moody and Perry, 1988, p. 68)

\section{Do Not Take Life for Granted}

Many NDErs change their attitude or approach toward life after an NDE. They feel life is very precious, and they have an increased appreciation of it. One NDEr wrote:

Life, what a beautiful and precious gift! Why do we take it for granted? I know I did before my accident but not anymore. Each day is beautiful and exciting because I am alive to enjoy it. I love the sunrise, the sunset. I watch the birds as they come to the feeder. I watch the little ants as they carry home their loads. I take each day as it comes. I don't live by hours and minutes or seconds anymore. Just day and night, and I am grateful for each new day. I am so grateful for the little things I can do with my hands, like write my name. (Nelson, 1988, p. 131)

\section{Love and Serve Others}

Many NDErs stress the importance in this life of trying to cultivate love for others. Ring states that the basic message that the NDEr comes away with is that knowledge and love are the most important things (Moody and Perry, 1988). Moody pointed out that after the NDE almost all experiencers "say that love is the most important thing in 
life. Many say it is why we are here. Most find it the hallmark of happiness and fulfillment, with other values paling beside it" (Moody and Perry, 1988, p. 3). Moody also noted that many people sense, when asked by the "being" during the life review of the NDE what is going on in their hearts, that the simple acts of kindness that come from the heart are the ones that are most important because they are the most sincere.

One NDEr said:

Before the accident I was a very competitive person, always wanting the highest grade, the best job, the most money. I think I'm different now. I think I love and appreciate other people more and have a stronger desire to do things for others. (Nelson, 1988, p. 47)

Another NDEr expressed it this way:

Among other things I learned that the most important thing we can do on this earth is to show consideration, love and kindness to others. There are no bonuses for position alone, nor power and wealth. We are judged by how we treat people, and what we do for others. (Nelson, 1989 , p. 153)

\section{Each Human Life has a Purpose}

One implication of the findings of near-death research is that each person's life has a purpose. Gallup found that some NDErs felt God had a plan for their lives (Gallup and Proctor, 1982), and Morse noted: "The feeling that there is a purpose to life is one of the results of many childhood NDEs" (Morse and Perry, 1990, p. 155).

Perhaps the point to be made here is best summed up with the words told to one NDEr by someone in the other world, whom she believed was her Father in Heaven, that she would know her mission in life as time went on (Nelson, 1988). This statement implies that all people have a purpose or mission in this earthly life.

\section{There is an Afterlife}

For most of the core NDErs in Ring's study (1980), the idea of life after death became not merely highly probable, but a veritable certainty. This statement seems to reflect the findings of a number of near-death researchers. NDEs essentially tell us that we are not 
snuffed out of existence by death. As one author pointed out: "This is important because - to a large degree-how we view death determines how we live life" (Nelson, 1988, p. 2). Generally the feelings of NDErs in regard to an afterlife are expressed in this statement: "Because of what had just happened I no longer just believed in an afterlife. I knew for a surety there was life beyond death because I had just been there" (Nelson, 1988, p. 67).

\section{Social Position and Wealth are Not Important}

After their NDEs, experiencers become less status conscious and materialistic. Lee Nelson noted a theme that recurs in several of his collected NDE accounts:

Wealth, power, position in the church, even attendance at church meetings didn't seem to matter-only what one did to improve conditions and lighten the burdens of others. Christian service and charity were far ahead of anything else in winning approval and peace for those entering the world of spirits. $(1989$, p. 12)

One NDEr said:

I also received the strong impression that positions at work, in society and in the church are not important at all. What matters is how we treat people, whether or not we are kind to them and what kind of relationship we build with our families. (Nelson, 1989, p. 21)

\section{Do Not Take Your Own Life}

A considerable amount of near-death research indicates that people should not take their own lives. Moody found suicide-related NDEs to be uniformly unpleasant. He quoted one woman as saying, "If you leave here a tormented soul, you will be a tormented soul over there, too" $(1975$, p. 143).

Ring and Stephen Franklin (1981-82) found a common testimony among suicide attempters they interviewed who had an NDE was that suicide had ceased to be an option. In one suicide-related NDE account, the experiencer was asked by a male voice whether he wanted to return to life, and he stated that he wanted to die. Then the male voice said: "You are breaking my laws to commit suicide. You'll not be with me in heaven-if you die" (Ring, 1980, p. 76). 
One of the child NDErs interviewed by Morse saw that some people remained in a void, especially those who had committed suicide (Morse and Perry, 1990). This scene seems to confirm what the male voice told the NDEr interviewed by Ring.

\section{Gain Knowledge}

Previously, we noted that Ring had stated that the basic message the NDEr comes away with is that knowledge and love are the most important things (Moody and Perry, 1988). Moody also noted in his first book that many NDErs he spoke with emphasized the importance of seeking knowledge. He wrote: "During their experiences, it was intimated to them that the acquisition of knowledge continues even in the afterlife" (1975, p. 93). Later Moody wrote that NDErs

have newfound respect for knowledge. Some say that this was the result of reviewing their lives. The being of light told them that learning doesn't stop when you die; that knowledge is something you can take with you. Others describe an entire realm of the afterlife that is set aside for the passionate pursuit of knowledge. (Moody and Perry, 1988, p. 35)

One NDEr while in the other world observed that people have their free agency there, just as we do here, and that gaining knowledge was the only way to progress (Crowther, 1967).

\section{Messages from Child NDErs}

In addition to these major lessons primarily from adult NDErs, Morse has also listed messages given exclusively to children who had NDEs:

The messages given to these children of the Light are not new or controversial. They are as old as mankind itself and have served as the primary fuel of our great religions:

"Love your neighbor and cherish life."

"Do unto others as you would have them do unto you."

"Clean up your own mess."

"Be the best you can be."

"Contribute to society."

"Be nice, kind, and loving."

These messages have a special urgency for those who have had neardeath experiences. Why? Perhaps since the messages came to them at 
the point of death, they must be important. (Morse and Perry, 1990, p. 163)

\section{Conclusion}

Just as these messages have a special urgency for the NDErs who receive them, shouldn't they also a special urgency and importance for humanity? Will humanity listen? National surveys in the United States provide a partial answer to this question, if we assume that belief in life after death and in a heaven would make a person receptive to lessons from NDEs. A series of Gallup Polls conducted in 1980-81 found that 67 percent of the general public acknowledged belief in life after death and 71 percent acknowledged belief in heaven (Gallup and Proctor, 1982). Additionally, this information about lessons from NDEs has been gathered through scientific investigations that may make the information more acceptable for some people; science is the official culture in our society and has become, so to speak, the court of last resort in determining what is true.

But will those who listen translate these lessons into correspondingly appropriate behavior? National surveys cannot measure social action; they can only collect self-reports of recalled past action, as in the case of NDEs, or of prospective or hypothetical action. In others words, there is not perfect correspondence between attitudes and behavior:

For instance, much research shows that how people act in an interracial group situation bears little or no relation to how they feel or what they think. The social context in which people find themselves does much to determine their specific responses. (Vander Zanden, 1988, p. 49)

Without having NDEs themselves, what people will do as a result of these important lessons from NDEs I believe goes to the heart of each individual. Perhaps disseminating these messages to the public may help to motivate many to live lives in accordance with the lessons from NDEs.

\section{References}

Atwater, P. M. H. (1988). Coming back to life: The after-effects of the near-death experience New York, NY: Dodd, Mead.

Bauer, M. (1985). Near-death experiences and attitude change. Anabiosis: The Journal of Near-Death Studies, 5(1), 39-47.

Clark, K. (1984). Clinical interventions with near-death experiencers. In B. Greyson and C. P. Flynn (Eds.), The near-death experience: Problems, prospects, perspectives (pp. 242-255). Springfield, IL: Charles C Thomas. 
Corcoran, D. K. (1988). Helping patients who've had near-death experiences. Nursing 88, 18(11), 34-39.

Crowther, D. S. (1967). Life everlasting. Salt Lake City, UT: Bookcraft.

Flynn, C. P. (1982). Meanings and implications of NDEr transformations: Some preliminary findings and implications. Anabiosis: The Journal of Near-Death Studies, 2, 3-14.

Flynn, C. P. (1986). After the beyond: Human transformation and the near-death experience Englewood Cliffs, NJ: Prentice-Hall.

Furn, B. G. (1987). Adjustment and the near-death experience: A conceptual and therapeutic model. Journal of Near-Death Studies, 6, 4-19.

Gallup, G., Jr., and Proctor, W. (1982). Adventures in immortality: A look beyond the threshold of death. New York, NY: McGraw-Hill.

Gomez, A. E. (1986). The aftereffects of near-death experience Unpublished dissertation, Ohio State University College of Nursing.

Green, T. J., and Friedman, P. (1983). Near-death experiences in a Southern California population. Anabiosis: The Journal of Near-Death Studies, 3, 7795.

Grey, M. (1985). Return from death: An exploration of the near-death experience. London, England: Arkana.

Greyson, B. (1983a). Near-death experiences and personal values. American Journal of Psychiatry, 140, 618-620.

Greyson, B. (1983b). Increase in psychic phenomena following near-death experiences. Theta, $11,26-29$.

Greyson, B., and Harris, B. (1987). Clinical approaches to the near-death experiencer. Journal of Near-Death Studies, 6, 41-52.

Greyson, B, and Stevenson, I. (1980). The phenomenology of near-death experiences. American Journal of Psychiatry, 137, 1193-1196.

Grof, S., and Halifax, J. (1977). The human encounter with death. New York, NY: Dutton.

Helene, N. (1984). An exploratory study of the near-death encounters of Christians. Unpublished dissertation, Boston University.

McLaughlin, S. A., and Maloney, N. H. (1984). Near-death experiences and religion: A further investigation. Journal of Religion and Health, 23, 149159.

Miller, J. S. (1987). A counseling approach to assist near-death experiencers: A response to Bette Furn's paper. Journal of Near-Death Studies, 6, 30-36.

Moody, R. A., Jr. (1975). Life after life Covington, GA: Mockingbird.

Moody, R. A., Jr., and Perry, P. (1988). The light beyond New York: NY: Bantam.

Morse, M., and Perry, P. (1990). Closer to the light: Learning from the near-death experiences of children. New York, NY: Villard.

Nelson, L. (1988). Beyond the veil Volume I. Orem, UT: Cedar Fort.

Nelson, L. (1989). Beyond the veil. Volume II. Orem, UT: Cedar Fort.

Noble, K. D. (1987). Psychological health and the experience of transcendence. Counseling Psychologist, 15, 601-614.

Noyes, R., Jr. (1980). Attitude change following near-death experiences. Psychiatry, 43, 234-241.

Papowitz, L. (1986). Life/death/life. American Journal of Nursing, 86, 417-418.

Ring, K. (1980). Life at death: A scientific investigation of the near-death experience. New York, NY: Coward, McCann and Geoghegan.

Ring, K. (1984). Heading toward omega: In search of the meaning of the neardeath experience New York, NY: Morrow.

Ring, K., and Franklin, S. (1981-82). Do suicide survivors report near-death experiences? Omega, 12, 191-208.

Sabom, M. B (1982). Recollections of death: A medical investigation. New York, NY: Harper and Row. 
Schaefer, M. T. (1988). Counseling after a near-death experience [Letter]. Journal of Near-Death Studies 7, 55-56.

Sutherland, C. (1990). Changes in religious beliefs, attitudes, and practices following near-death experiences: An Australian study. Journal of NearDeath Studies, 9, 21-31.

Vander Zander, J. W. (1988). The social experience: An introduction to sociology. New York, NY: Random House.

Walker, B. A. (1989). Health care professionals and the near-death experience. Death Studies, 13, 63-71. 